\title{
Saudades de Cantagalo: nuevos datos sobre la desconocida biografía brasileña de Américo Castro
}

\author{
Saudades de Cantagalo: novos dados sobre a desconhecida biografia brasileira de \\ Américo Castro
}

\author{
Saudades de Cantagalo: new data on the unknown Brazilian biography of \\ Américo Castro
}

AUTOR

Pablo González Velasco*

p.gonzalez@usal.es

* Doctorando en Antropología por la Universidad de Salamanca (USAL, España).

\section{RESUMEN:}

El texto es el resultado de una investigación sobre la brasileñidad de Américo Castro, a través de las fuentes locales de Cantagalo (Rio de Janeiro, Brasil), su municipio natal, y la hemeroteca brasileña. La investigación aborda diferentes ámbitos: la ubicación de la casa de nacimiento, la situación de la familia, las actividades de su visita en 1946, sus impresiones de Cantagalo, los reconocimientos post mortem, así como las "saudades" que expresaba por carta a sus amigos brasileños. Sin pretender cuestionar, en líneas generales, las interpretaciones de sus discípulos, cabe realizar nuevos análisis biográficos complementarios, dando énfasis a su primera infancia brasileña (lusófona) y su capacidad de comprensión de la pluralidad étnica.

\section{RESUMO}

O texto é fruto de uma pesquisa sobre a brasilidade de Américo Castro através de fontes locais em Cantagalo (Rio de Janeiro, Brasil), seu município de origem, e de arquivo de jornais brasileiros. A pesquisa aborda diferentes aspectos: a localização da casa onde nasceu, a situação da família, as atividades da sua visita em 1946, suas impressões de Cantagalo, os reconhecimentos post-mortem e as "saudades" que ele expressou em carta a seus amigos brasileiros. Sem pretender questionar, em termos gerais, as interpretações de seus discípulos, é possível realizar novas análises biográficas complementares, enfatizando sua infância brasileira (lusófona) e sua capacidade de entender a pluralidade étnica.

\footnotetext{
ABSTRACT:

This paper is a result of a research on the Brazilianity of Américo Castro, through local sources in Cantagalo (Rio de Janeiro, Brazil), his native municipality, and the Brazilian newspaper archive. The research deals with different areas: the location of the birth house, the situation of the family, the activities of his visit in 1946, his impressions of Cantagalo, post-mortem recognitions, as well as "saudades" that he expressed by letter to his Brazilian friends. Without intending to question, in general terms, the interpretations of his disciples, it is possible to carry out new complementary biographical analyzes, emphasizing his early Brazilian childhood (lusophone) and his ability to understand ethnic plurality.
} 
A los 135 años del nacimiento del filólogo, antropólogo e historiador Américo Castro (Cantagalo, 4 de mayo de 1885 - Playa de Aro, 25 de julio de 1972), me puse en contacto con instituciones en Cantagalo ${ }^{1}$ para confirmar el nacimiento e investigar la huella de D. Américo en el municipio, famoso porque allí nació también el célebre escritor Euclides da Cunha.

El primer contacto fue con Matheus Lucas de Arruda Câmara, asesor municipal de Cultura, que me facilitó la interlocución con Wesley da Silva Gonçalves, historiador y coordinador local del Centro de Memória, Pesquisa e Documentação de Cantagalo². Wesley Gonçalves, cuya participación fue decisiva, tenía conocimiento del nombre del intelectual hispano-brasileño por haber leído sus cartas en el acervo legado por la familia de Edmo Rodrigues Lutterbach (19312011), expresidente de Academia Fluminense de Letras y amigo de Américo Castro. En un trabajo de investigación conjunto, encontramos la casa de nacimiento de Américo Castro y varios testimonios de su huella en Cantagalo, así como de los trazos de su brasileñidad. Las cartas a Rodrigues Lutterbach suponen también uno de los últimos testimonios de Castro antes de su fallecimiento.

\section{1. ¿En qué casa nació?}

Por el certificado de bautismo, sabemos que Américo Castro nació en Cantagalo el 4 de mayo de 1885, hijo de Antonio de Castro Pérez y Carmen Quezada Gálvez. Fue bautizado, el 14 de junio de 1885, en la iglesia matriz del Santísimo Sacramento de Cantagalo, que existe en perfectas condiciones. Según Gilberto Freyre: "o seu nome Américo é o que recorda por vontade paterna: o fato de ter nascido em terra americana" (Freyre, 1953).

Por una biografía del Acervo Edmo Rodrigues Lutterbach, en portugués, sabemos que los padres de Américo Castro, oriundos de Granada, llegaron en el último cuarto del siglo XIX y se instalaron como "negociantes", en un momento donde la región (centro fluminense) vivía "um esplendor nunca mais alcançado". Lo hicieron como tantos otros inmigrantes españoles, portugueses y suizos. Era el momento del apogeo y fin abrupto del ciclo del café en el interior de Río de Janeiro, que termina justamente en los primeros años de vida de Américo Castro, lo que obliga a la familia Castro a volver a España. La causa de esta crisis fue la utilización predatoria de la tierra, que coincide en el tiempo con la abolición de la esclavitud.

Edmo Rodrigues Lutterbach cuenta que el nombre del padre de Américo Castro, Antonio de Castro, "aparece em primeiro lugar na relação dos comerciantes daquela cidade, existente no Almanak Laemmert de 1880, página 91". En el Diário de Notícias (1886 y 1887) de Río de Janeiro, aparecen visitas de Antonio de Castro Péres como "importante negociante". Incluso, en 1888, fue nombrado miembro de la comisión para "encarregar-se de dirigir as obras da igreja matriz do Santíssimo Sacramento da cidade de Cantagallo" (O Fluminense, 1888).

La primera pista sobre el lugar de nacimiento aparece en el artículo de Edmo Rodrigues Lutterbach en O Fluminense del 7 de diciembre de 1970: "nasceu numa casa da rua conhecida atualmente por Getúlio Vargas, onde eram comercialmente estabelecidos" (Rodrigues, 1970). La calle Getúlio Vargas tenía el nombre de calle Mão de Luva en la infancia de Américo. Sabiendo
PALABRAS CLAVE

Américo Castro;

Cantagalo; Brasil;

Gilberto Freyre.

PALAVRAS-CHAVE

Américo Castro;

Cantagalo; Brasil;

Gilberto Freyre.

KEYWORDS

Américo Castro;

Cantagalo; Brasil;

Gilberto Freyre.

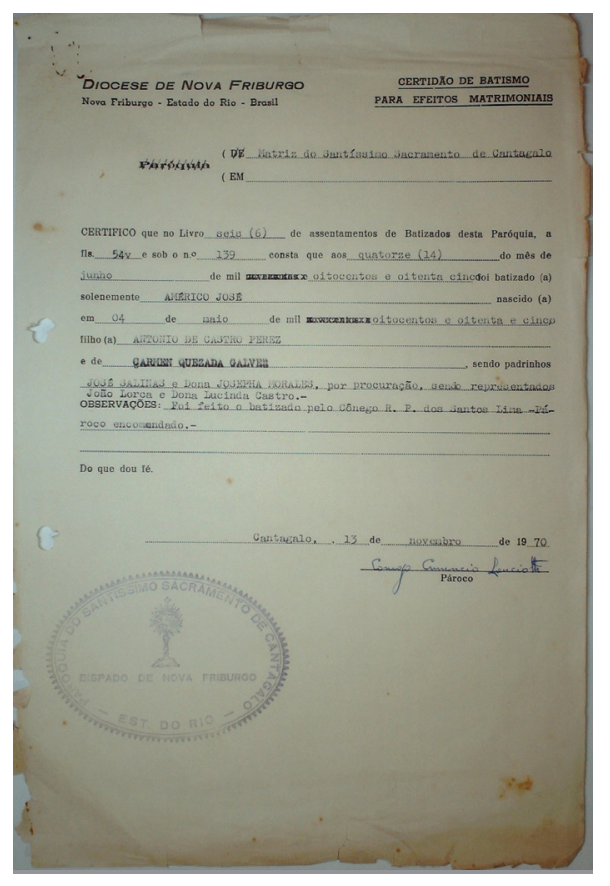

Imagen 1. Certificado de bautismo. Fuente: Acervo Edmo Rodrigues Lutterbach. 
que la casa estaba en el mismo lugar que el comercio familiar, el siguiente paso fue encontrar un negocio familiar con el nombre del padre de Américo.

Wesley da Silva Gonçalves y yo, encontramos el nombre del establecimiento: "Bazar Hespanhol". Sito en la calle Mão de luva, 22 (O Voto Livre, 1887). En los anuncios del bazar se promocionaba la venta de productos, una liquidación por reforma y la compra de café, así como se ofrecían servicios financieros para inmigrantes ibéricos que querían enviar dinero a la Península.

Por los datos recogidos hasta el momento, confirmados por el profesor Gilberto Cunha, la casa de nacimiento de Américo Castro (Bazar Hespanhol) se situaría a 22 metros de la esquina de las calles Barão de Cantagalo y Maestro Joaquim Antônio Naegele, en dirección opuesta a la Praza João XXIII. El actual edificio de la casa, de los años 1930, no corresponde con el original. La dificultad añadida es que la calle, por ese tramo, cambió de nombre dos veces: de Mão de Luva a Getúlio Vargas, y de este a Avenida Barão de Cantagalo.

\section{El retorno del hijo pródigo en 1946}

Américo Castro permaneció en suelo brasileño, invitado por el Itamaraty, durante 47 días, entre el 2 de junio y el 19 de julio de 1946, en tiempos constituyentes bajo el gobierno del presidente Eurico Gaspar Dutra. Castro dio un curso de diez conferencias (A Noite, 12 de junio de 1946) sobre la historia de los pueblos ibéricos y de la literatura española (con referencias al Quijote y La Celestina), en la Facultad Nacional de Filosofía de Río de Janeiro, y fue homenajeado por el Ministerio de Relaciones Exteriores brasileño y por la Academia Brasileira de Letras ( $A B L$, convirtiéndose en correspondiente). También dio conferencias en Minas Gerais y São Paulo (donde habló sobre Cervantes y A origem do gênero literário-romance en la Biblioteca Municipal). El filólogo e historiador español explicó los contenidos del curso en una entrevista al periódico $A$ Noite de Río de Janeiro:

O público de professores e alunos seguiu com animadora simpatia o desenvolvimento da nova e difícil ideia de terem sido os mouros e os judeus tão importantes como os cristãos na formação da personalidade mais intima de espanhóis e portugueses. Tive a impressão de estar mantendo um diálogo espiritual com aquele distinto auditório (A Noite, 4 de julio de 1946).

En este curso, en Río de Janeiro, presenta su nuevo método de interpretación de la civilización ibérica, dado que fue realizado dos

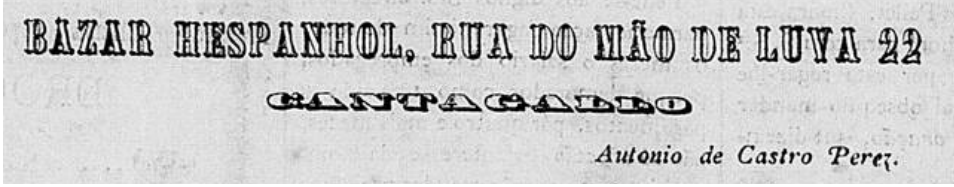

Imagen 2. Anuncio en prensa del negocio de la familia Castro. Fuente: O Voto Livre (1887, 13 de noviembre), p. 4. Disponible en [http://memoria.bn.br/ DocReader/817236/12 ]. Consultado [08-05-2020].
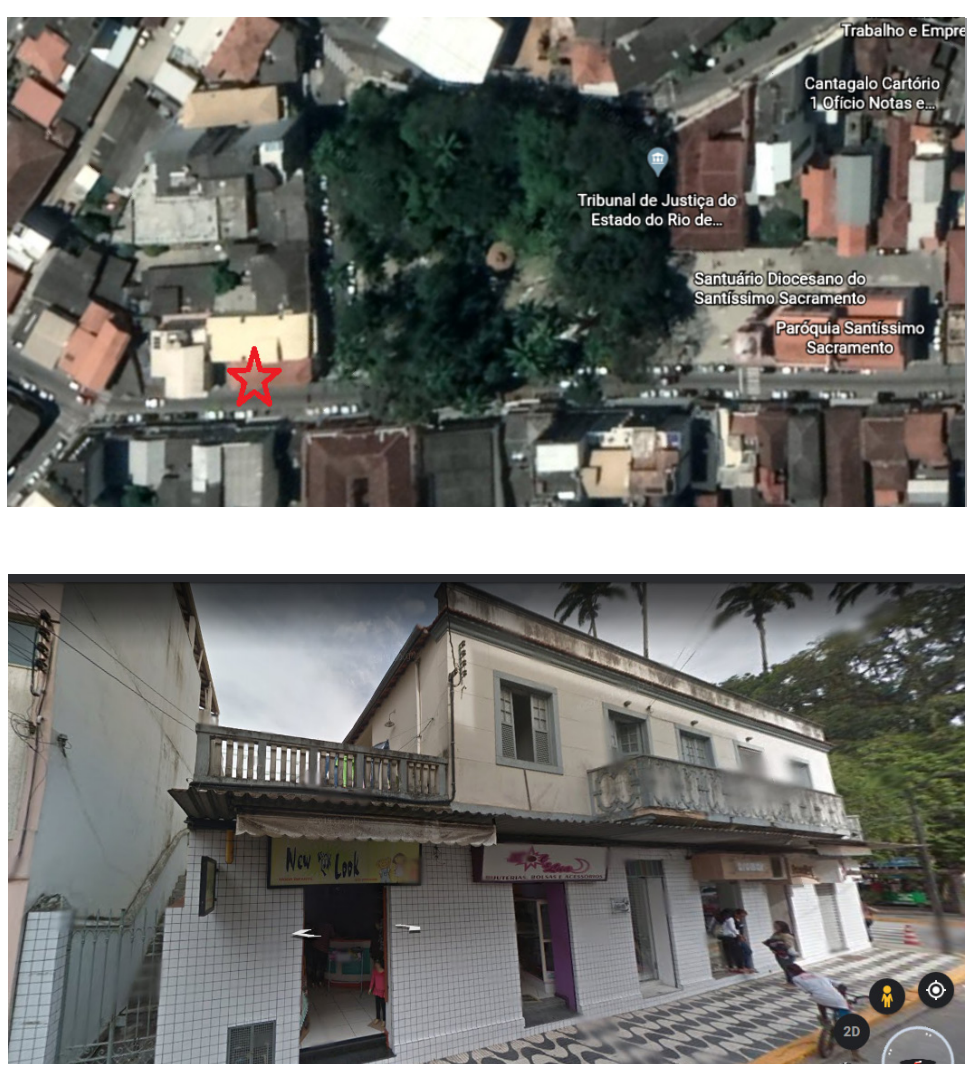

Imágenes 3 y 4 . Ubicación de la casa natal. Rua Mão de luva, 22. Fuente: Elaboración propia con Google Maps. 
años antes de publicar La España en su historia: cristianos, moros, judíos (1948), libro actualizado y ampliado en La realidad histórica de España (1954). Por otro lado, la Universidad de Rio de Janeiro le otorgó el título de doctor honoris causa. También dio una conferencia sobre Dom Quixote e Cervantes en el P.E.N Club. En unas declaraciones para el Correio da Manhã, Américo Castro dejó sus impresiones sobre Río de Janeiro:

Surpreendeu-me gratamente o convite porque creio ser o primeiro professor chamado a tratar no Brasil de questões relacionadas com a civilização hispânica. O afastamento secular de Portugal e Espanha tem no Brasil seu reflexo natural. (...) Os problemas daqui em nada se assemelham aos do México ou de Buenos Aires, e Nova York pertence já a outro planeta. Pelo jeito da vida carioca corre mansamente toda a história passada, como um rio que vai recebendo afluentes. Sinto aqui a vibração lírica e fidalga da tradição lusitana, os ecos do Império junto ao rumor da população de origem africana, articulada e harmonizada em escalas de humanidade; o homem vale pelo seu valor e não pela sua cor. Não concebo o Rio como uma realidade limitada, senão como um símbolo e expressão de uma estrutura humana absurdamente vária e sem embargo coerente, ainda que indefinível em termos lógicos. Só um artista genial poderia traduzir em uma expressão tão estranha sinfonia humana (Correio da Manhã, 25 de junio de 1946).

La visita a su pueblo, Cantagalo, tras 57 años de ausencia, se produjo el 30 de junio, "chegando às primeiras horas da manhã, proveniente de Friburgo, onde pernoitara, e regressando a Niterói e Rio no dia imediato, $1^{\circ}$ de julho", según la biografía del Acervo Edmo Rodrigues Lutterbach.

En Cantagalo dio una conferencia ${ }^{3}$ a sus paisanos. Fue acompañado por su esposa Carmen Madinaveitia, "do jornalista José Cándido de Carvalho e senhora, e do insigne Professor do Liceu Nilo Peçanha e da Facultade de Filosofia, Ciências e Letras da Capital fluminense, Dr. Baltazar Xavier" (Rodrigues, 1970). Américo Castro contó su experiencia en Cantagalo:

Fui lá pelo desejo de conhecer minha cidade natal. Venho encantado com ela. Uma pequena e deliciosa cidade de ruas largas e limpas, bem traçada, singela mas cheia de vida. Ali as coisas se tocam de um ar civilizado. A própria cadeia parece um hotel. Há pessoas de boa cultura. Tive surpresas até no domínio da filosofia. As moças de lá não são apenas bonitas e amáveis mas cultas e interessadas pelos problemas de ordem geral. Gostei de conversar com elas. A cidade apesar da pequena população que possui, desfruta de uma vida intensa. É um curioso exemplo de municipalismo, mas tem também características intelectuais de um grande centro. Não sou estranho as fases críticas por que passou Cantagalo; tenho, por isso, a impressão de que renasce nesta hora. Suas fazendas de gado e café reconquistam uma economia seriamente ameaçada. Dão-lhe, porém, o lastro econômico para estimulara nova fase que atravessa. É curioso recordar o palácio ${ }^{4}$ que lá deixou o barão de Nova Friburgo. Seu atual proprietário, filho da quem o havia adquirido, está tentando restaurar o palácio em suas linhas tradicionais, removendo para lá o mobiliário disperso e restabelecendo o ambiente, no que contribui para a restauração de um monumento. Mas não é apenas isso: esse moço é um espírito moderno e empreendedor, e está transformando a fazenda numa fazenda moderna, à maneira dos homens de visão larga, consagrando suas energias à terra, com amor e cultura. Pelo que vê, venho encantado de Cantagalo. Foi para mim uma alegria testemunhar a sua vitalidade e o surpreendente aspecto de civilização que oferece, apesar de seus poucos recursos. Um belo exemplo, enfim, de cidade interior! (A Noite, 4 de julio de 1946).

\section{Saudades de Cantagalo}

En una tarjeta sin fecha, Américo Castro confiesa a su paisano Edmo Rodrigues Lutterbach: "Siempre recuerdo mi nacimiento en Cantagalo y mi visita en 1946, con ninguém na cadeia! (...) Meu portugués não é bom e é por isso que escrevo em castelhano. Obrigadíssimo e honradíssimo". En una carta a Edmo Rodrigues Lutterbach, fechada el 29 de mayo de 1972 en Madrid, a menos de dos meses de morir don 
Américo, este afirma:

Distinguido y muy estimado paisano (é a palabra española para conterrâneo): É uma mágoa não poder escrever a língua que falava a idade de cinco anos mas a vida é como é. Recuerdo su artículo en "O Fluminensse" de Niterói, y me conmovió su afectuosa "lembrança", que agradecí mucho. A mi edad, 87 años, me encuentro lleno de ecos y saudades de orígenes muy varios, -algo así como una vieja roca con estratos de diferente composición-. (...) Durante toda mi vida de pensador consciente me ha preocupado la incapacidad hispano-lusitana para vivir democráticamente, sin tener que optar entre la anarquía, la oligarquía o las arbitrarias y férreas dictaduras. La explicación me la ha dado la forma de estar integrada la población de la Península Ibérica. Pero no tengo tiempo ni fuerzas para explicar lo que ya está en mis libros. (...) Lo publicado por mí, después de 1940, aspira a dar a los españoles una explicación de por qué hemos venido ignorando quienes somos, y porque los hispanos se matan ciegamente los unos a los otros. No me interesa la erudición, no tengo ninguna pretensión de sabiduría; desearía abrir los ojos de los ciegos, nada más. Algunos comienzan a darme la razón y a defenderme. Cuando escribo sobre España, pienso también en el Brasil, en Hispanoamérica, en Portugal. Lembro-me as vezes de Cantagalo, nossa cidadinha, ¡com ninguém na cadeia em 1946! O coração é demasiado pequeno para conter as complicações da nossa vida. Um apertado abraço deste seu conterrâneo.

Existe otra carta ${ }^{5}$ dirigida a Edmo Rodrigues Lutterbach, escrita por Américo Castro, desde el Hotel Rigat en Girona, 15 días antes de morir, fechada el 10 de julio de 1972:

Es en verdad impresionante que se acuerden de mí mis paisanos de Cantagalo, lugar conocido por mí, más que por mis recuerdos personales, por lo referido por mi madre, para quien los 14 años pasados en Cantagalo fueron los únicos en que se sintió feliz. Tuvo ocasión de ver allá al emperador Dom Pedro [II], y entabló amistades con familias cantagalenses para ella siempre presentes. (...) Lo dicho por Ud. en el "Conselho Estadual de Cultura"' me llega muy al alma. Un día vendrá en que -superados los odios- se vea que mis explicaciones del pasado en la Península Ibérica pueden interesar incluso al Brasil, a través de Portugal.

\section{Reconocimientos post mortem en Brasil}

El día 30 de septiembre de 1972, el Conselho Municipal de Cultura de Cantagalo organizó unas conferencias sobre la vida de Américo Castro "cantagalense internacional", poco después de su muerte (O Fluminense, 28 de septiembre 1972). El 14 de marzo de 1975, el periódico O Fluminense anuncia:

Em reunião realizada no Instituto Histórico de Niterói, o Promotor de Justiça Edmo Rodrigues Lutterbach, que é vice-presidente do Órgão, fez uma palestra sobre os cantagalenses Américo Castro e Eduardo Chapot-Prevost. (...) A Academia

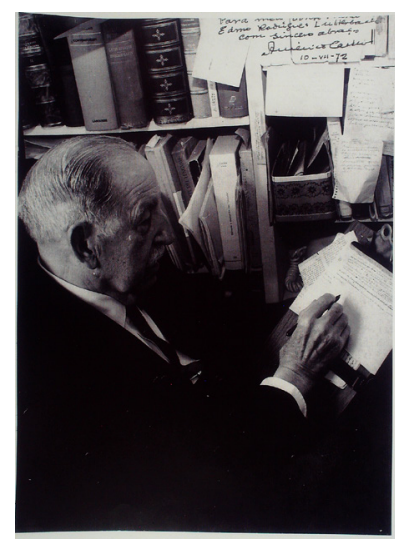

Imagen 7. Américo Castro. Fuente: Acervo Edmo Rodrigues Lutterbach. 
Niteroiense de Letras, por proposta sua, criou uma Cadeira [48], que tem por patrono Américo Castro ${ }^{7}$ (O Fluminense, 14 de marzo y 23 de septiembre de 1973).

\section{Primeras conclusiones}

Hasta ahora se había considerado, en la historiografía española sobre Américo Castro, que su nacimiento en Brasil fue "accidental", y probablemente, por falta de información, escasamente relevante para su biografía. Sin pretender cuestionar, en líneas generales, las interpretaciones de sus discípulos, cabe realizar nuevos análisis complementarios, dando énfasis a su primera infancia brasileña (lusófona), alimentada por varios motivos: 1) los recuerdos contados de una madre que era feliz en Brasil; 2) el viaje de regreso del hijo pródigo de 1946; y 3) la amistad con Edmo Rodrigues Lutterbach, Baltazar Xavier y Gilberto Freyre.

Américo Castro, cuando vio Granada, por primera vez, lo hace con un bagaje cultural granadino por la herencia de sus padres, pero también lo hace desde un bagaje y una óptica lusotropical, donde la pluralidad, la violencia y el mestizaje étnico eran elementos consustanciales al paisaje cotidiano brasileño. E, incluso, sus propios padres vivieron 14 años en Brasil, por tanto, se presupone un grado importante de aculturación brasileira. Más si cabe si hablamos de sus hermanos (todos nacidos antes que él), según indican los registros eclesiásticos, Lucinda (03/07/1877), Gabriel (19/11/1879), Antonio (19/05/1882) y Américo (04/05/1985). Haciendo las cuentas, si salieron de Brasil aproximadamente a finales de 1889, llegaron a Granada con 12 , 10, 7 y 4 años, respectivamente, aunque don Américo siempre lo redondeaba a 5 años. Su iberismo espiritual se confirma en una de las cartas a Edmo (29/05/1972), al afirmar que: "cuando escribo sobre España, pienso también en el Brasil, en Hispanoamérica, en Portugal". Se trata del mismo método de Gilberto Freyre, cuando el pernambucano considera que España, a través de Ángel Ganivet, le ayuda a ver Brasil.

Gilberto Freyre (1953) cuenta cómo, junto con Fidelino de Figueiredo, intentó traer a Brasil a Américo Castro en el marco de un intento de "valorizar a vida intelectual brasileira com a presença de Américo Castro, numa catédra que o prendesse para sempre ao Rio ou a São Paulo". No pudo ser por razones políticas, pese a la voluntad de don Américo de "integrar-se na vida intelectual brasileira". Este deseo no encontro "repercussão nos meios oficiais no Rio, onde, em 1937, tais assuntos eram decididos de modo às vezes cruamente simplista". No obstante, Américo Castro pudo servirse de su nacionalidad brasileña para entrar en los Estados Unidos, tras un breve periplo por Buenos Aires (González, 2014) ${ }^{8}$.

Américo Castro fue embajador de España en Alemania, miembro de la Asociación Unión Iberoamericana y de la generación de la "Escuela de Madrid"9 , historiador de la cultura y literatura, filólogo, antropólogo, catedrático en Princeton y estudioso de la obra de Cervantes. Discípulo de Ramón Menéndez Pidal. Gran rehabilitador de la herencia andalusí (hispanomusulmana e hispanojudía) y de la identidad granadina. Mundialmente reconocido por las universidades de más renombre en Europa, Estados Unidos e Iberoamérica. Amigo de Federico de Onís, Gilberto Freyre y Julián Marías. Enemigo de Sánchez Albornoz, con quien protagonizó una de las más épicas polémicas sobre la interpretación de España. Se trata, por tanto, de un ibérico universal.

Américo Castro siempre admiró al emperador brasileño Pedro II. A finales de 1889, ambos salieron de Brasil camino de Europa, camino de lberia. Américo fue uno de los últimos niños del Imperio de Brasil, antes de la proclamación de la República. En el caso de don Américo, la vida le dio la oportunidad de volver y lo hizo. Sus saudades nos dan muestra de la perseverancia de sus raíces lusotropicales. En una carta a su amigo Baltazar Xavier ${ }^{10}$, enviada desde Colorado (Estados Unidos), el 8 de julio de 1947, le diría:

A lembrança da cara e meiga cidadezinha, Cantagalo, enche-me o coração. E é a você, bom Baltazar, só a você, que eu devo o prazer e a honra da viagem - como a do filho pródigo. Não me esqueço não. Não tenciono voltar oficialmente ao Brasil, mas sim como simples viageiro. E de voltar a Cantagalo. Quisera morar lá o ano próximo como turista (Rodrigues, 1970). 
Transcurridos algunos años, por ocasión del centenario de Cantagalo, volvió a escribir a Baltazar, desde Princeton, el 11 de diciembre de 1957. Le pidió saludar a Carlos Bellieni Éboli y la profesora y poetisa Amélia Thomaz, y le confesó que "Ójala fuera posible volver alguna vez por el Brasil y pasar unos días de reposo en Cantagalo" (Rodrigues, 1970). No pudo ser.

Los restos mortales de Américo Castro reposan en el Cementerio Civil de Madrid, lejos de Brasil. Sin embargo, su memoria puede ser muy útil para estrechar relaciones entre España y Brasil, entre Granada y Cantagalo. Que los estudiantes de Cantagalo empiecen a conocer, por ejemplo, su libro Iberoamérica: su historia y su cultura (Hold, Rinehart and Winston, INC. 1954 -Nueva edición ampliada 1962-), donde habla también de Brasil, podría ser una gran iniciativa. O como la que propone Wesley da Silva Gonçalves, con mi apoyo y el del concejal João Bôsco, de crear el día de la inmigración española en Cantagalo, iniciándola con un homenaje, con algún elemento material, como una placa, para inmortalizar la memoria de don Américo. Sobre las posibles efemérides a celebrar, además del nacimiento (acaba de cumplirse su 135 aniversario), tenemos el 30 de junio de 2021 (1946): que se cumplen 75 años de la visita de Américo Castro a Cantagalo. Y el 25 de julio de 2022 (1972): que se cumplen 50 años de su muerte. En el obituario, su amigo Edmo dejó claro que "Cantagalo não o esquecerá

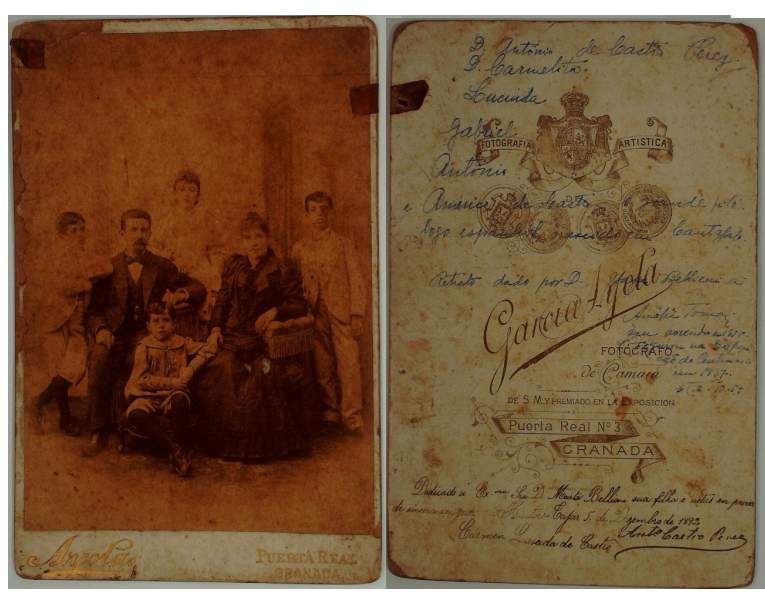

Imagen 8. Familia Castro en Granada. Fuente: Acervo Edmo Rodrigues Lutterbach. 


\section{NOTAS}

1 El municipio de Cantagalo (Cantagallo, en grafía antigua) está en el interior del estado de Río de Janeiro; no confundir con la favela, del mismo nombre, ubicada en la ciudad de Río de Janeiro.

${ }^{2}$ El Centro de Memória, Pesquisa e Documentação de Cantagalo (CMPD-CAN) existe desde 2010 y funciona en el Polo CEDERJ-UAB/Cantagalo - RJ. El CMPDCantagalo está vinculado al curso de Licenciatura en Historia de la Universidade Federal do Estado do Rio de Janeiro (Unirio), en la modalidad de enseñanza a distancia/EAD-UNIRIO y al programa de postgrado en Historia de la Unirio. Se trata de un archivo histórico que organiza y mantiene acervos documentales virtuales y bibliográficos, relativos a la historia de Cantagalo; además de proponer y desenvolver proyectos pedagógicos y de investigación.

${ }^{3}$ Según testimonio de Carlos Bellieni Eboli; Carta de lector a Gilberto Freyre en O Cruzeiro (6 de junio de 1953). Carlos Bellieni Eboli fue quien organizó el viaje a Cantagalo por la amistad entre ambas familias.

${ }^{4}$ Se refiere al Palacete do Gavião.

${ }^{5}$ Le envió también una fotografía y una entrevista a $A B C$ de mayo de 1972.

${ }^{6}$ Américo Castro se refiere al siguiente reconocimiento que cuenta Edmo Rodrigues: "Em sessão do Conselho Estadual de Cultura realizada a 13 de junho passado [1972], propusemos a consignação em ata de voto de congratulações pelo transcurso do octogésimo sétimo aniversário natalício de Américo Castro, falando, na oportunidade de sua vida e obras, em especial, de suas atividades culturais. Aprovada, por unanimidade pelo Plenário, a proposição foi mimeografada, fazendo o digníssimo Presidente do Órgão, Dr. Paulo de Almeida campos, a comunicação oficial ao aniversariante". (Rodrigues, 11 de septiembre de 1972)

${ }^{7}$ ANL. Patronos das Cadeiras da Academia Niteroiense de Letras. Disponible em [http://www.academianiteroiense. org.br/patronos.htm]. Consultado [08-05-2020].

8 También en: Salvador Bernabéu, A. (2002). Varias incógnitas que Bernabéu se pregunta en relación a la brasileñidad de Castro, quedan aclaradas con los datos de la presente publicación. Bernabéu menciona que los alumnos de Castro entonaban, con la música del conocido himno de Riego, la siguiente coplilla: "Don Américo Castro y Quesada/ un señor que nació en el Brasil,/ pero luego se vino a Granada,/ a estudiar el derecho civil./ Institución o muerte,/ es siempre su divisa,/ y no va nunca a misa/ porque es un hombre civil".

${ }^{9}$ En la antigua facultad de Filosofía de la Universidad de Madrid, en Moncloa, existe una (sala de) aula con el nombre de Américo Castro, como homenaje.

10 También mencionada en Cassiano Nunes (1999, p. 5), y en Vamireh Chacon (2005, p. 56). Chacon afirma que Américo Castro "nunca esqueceu" Brasil. En un fragmento de la carta pide que "si tiene ocasión de ver a Carlos Bellieni y a los demás amigos, haga el favor de transmitirles mi afectuoso recuerdo". 


\section{REFERENCIAS BIBLIOGRÁFICAS}

A Noite (1946, 12 de jun.). Letras e Artes. Edição 12284. p. 20. Recuperado de [http://memoria.bn.br/ DocReader/348970_04/40383]. Consultado [08-052020].

A Noite (1946, 4 de jul.). Cativo dos Encantos da Terra Natal. Entrevista a Américo Castro. Edição 12303. p.1. Recuperado de [http://memoria.bn.br/ DocReader/348970_04/40768]; p. 18, recuperado de [http://memoria.bn.br/docreader/348970_04/40777 ]. Consultado [08-05-2020].

A Noite (1946, 5 de jul.). Conferências. Edição 12304. p. 20. Recuperado de [http://memoria.bn.br/ DocReader/348970_04/40801]. Consultado [08-052020].

ANL. Patronos das Cadeiras da Academia Niteroiense de Letras. Recuperado de [http://www.academianiteroiense. org.br/patronos.htm ]. Consultado [08-05-2020].

Bellieni Éboli, C. (1953, 6 de jun.) Carta a Gilberto Freyre. O Cruzeiro, ed. 34, p. 6. Recuperado de [http://memoria. bn.br/DocReader/003581/86657]. Consultado [08-052020].

Biografía de Américo Castro en portugués. Acervo Edmo Rodrigues Lutterbach.

Chacon, V. (2005). A grande Ibéria. Brasília: UNESP Editora/Paralelo15.

Correio da Manhã (1946, 25 de jun.). Um estudioso da literatura e da história ibérica (ed. 15840, p. 2). Recuperado de [http://memoria.bn.br/DocReader/089842_05/31888]. Consultado [08-05-2020].

Diário da Noite (1946, 28 de jun.). Américo de Castro. Sua conferência hoje, na F. de Filosofia, p. 13. Recuperado de [http://memoria.bn.br/DocReader/221961_02/34145]. Consultado [08-05-2020].

Diário de Notícias (1886, 16 de jul.). Hospedes e viajantes (año II, no 403, p.1). Recuperado de [http://memoria. bn.br/DocReader/369365/1645]. Consultado [08-052020].

Diário de Notícias (1887, 6 de ago.). Hospedes e viajantes (año III, $\mathrm{n}^{\circ}$ 788, p.1). Recuperado de [http:// memoria.bn.br/DocReader/369365/3199]. Consultado [08-05-2020].

Freyre, G. (1953, 23 de sep.). Ainda a propósito de Américo Castro. O Cruzeiro, p. 26. Recuperado de [http://memoria.bn.br/DocReader/003581/88133]. Consultado [08-05-2020].

Gazeta de Notícias (1946, 1 de jun.). Américo Castro llegará mañana a Brasil (ed. 125, p.11). Recuperado de [http://memoria.bn.br/DocReader/103730_07/27063]. Consultado [08-05-2020].
Gazeta de Notícias (1946, 18 de jul.). Academia Brasileira de Filologia. Recebido em sessão solene, o Prof. Américo Castro, catedrático de uma universidade ianque (ed. 165, p. 5). Recuperado de [http://memoria. bn.br/DocReader/103730_07/27565]. Consultado [0805-2020].

Gazeta de Notícias (1946, 20 de jul.). Seguiu para Buenos Aires o catedrático de Civilização Ibérica da Universidade de Princeton (ed. 167, p. 8). Recuperado de [http://memoria.bn.br/DocReader/103730_07/27592]. Consultado [08-05-2020].

Gazeta de Notícias (1946, 25 de jun.). Conferências (ed. 145. p. 7). Recuperado de [http://memoria.bn.br/ DocReader/103730_07/27315]. Consultado [08-052020].

Gazeta de Notícias (1946, 29 de jun.). Almôço no Itamarati, em homenagem a Sir Howard Florey, Emile Henriot e Américo Castro (ed. 149. p. 8). Recuperado de [http://memoria.bn.br/DocReader/103730_07/27364]. Consultado [08-05-2020].

González Herrán, J. M. (2014). José Rubia Barcia: unha vida contada. Consello da Cultura Galega. Recuperado de [http://consellodacultura.gal/mediateca/extras/ CCG_2014_Jose-Rubia-Barcia-unha-vida-contada.pdf]. Consultado [08-05-2020].

Jornal de Notícias (1946, 12 de jul.). Sociedade (ed. 75. p. 4). Recuperado de [http://memoria.bn.br/ DocReader/583138/664]. Consultado [08-05-2020].

Nunes, C. (1999). Américo Castro: de Cantagalo a Princeton. Brasília: Roberval Ed.

O Fluminense (1888, 14 de mar.). Noticiario $\left(\mathrm{n}^{\circ}\right.$ 1528 , p. 1). Recuperado de [http://memoria.bn.br/ DocReader/100439_02/5095]. Consultado [08-05-2020].

O Fluminense (1972, 28 de sep.). Cantagalo inicia amanhã os festejos da fundação (p. 6). Recuperado de [http://memoria.bn.br/docreader/100439_11/10070]. Consultado [08-05-2020].

O Fluminense (1973, 23 de sep.). Assembleia na Academia (ed. 21494, p.15). Recuperado de [http://memoria.bn.br/ docreader/100439_11/17385]. Consultado [08-05-2020].

O Fluminense (1975, 14 de mar.). Promotor lembra Américo Castro (ed. 21946, p. 7). Recuperado de [http://memoria.bn.br/docreader/100439_11/28798]. Consultado [08-05-2020].

O Voto Livre (1887, 13 de nov.). Anuncio: Sacca à bista sobre o banco commercial de Lisboa (p. 4). Recuperado de [http://memoria.bn.br/DocReader/817236/12]. Consultado [08-05-2020].

Rodrigues Lutterbach, E. (1970, 7 de dic.). Américo Castro. Um cantagalense na Espanha e no Mundo. 
Niterói: O Fluminense (ed. 20911, p. 34). Recuperado de [http://memoria.bn.br/DocReader/100439_11/78242]. Consultado [08-05-2020].

Rodrigues Lutterbach, E. (1972, 11 de sep.). Américo Castro. Cantagalense universal. O Fluminense (p. 4). Recuperado de [http://memoria.bn.br/ docreader/100439_11/9740 Edição 21177]. Consultado [08-05-2020].

Salvador Bernabéu, A. (2002), Un señor que llegó del Brasil. Américo Castro y la realidad histórica de América. Revista de Índias, LXII(226), 651-674. Recuperado de [http://revistadeindias.revistas.csic.es/index.php/ revistadeindias/article/view/467/535]. Consultado [0805-2020].

Correspondencia con Edmo Rodrigues Lutterbach:

Tarjeta sin fecha de Américo Castro.

Carta de Américo Castro. 29 de mayo de 1972 (Madrid).

Carta de Américo Castro. 10 de julio de 1972 (Hotel Rigat, Girona). 